\title{
Haemodialysis in Diabetic Patients Modulates Inflammatory Cytokine Profile and T Cell Activation Status
}

\author{
A. Almeida, O. Lourenço \&t A. M. Fonseca
}

CICS-UBI, Centro de Investigação em Ciências da Saúde, Universidade da Beira Interior, Covilhã, Portugal

Received 3 February 2015; Accepted in revised form 23 April 2015

Correspondence to: A. M. Fonseca, PhD, Department of Medical Sciences, Faculty of Health Sciences, University of Beira Interior, Avenida D. Afonso Henriques, 6200-506 Covilhã, Portugal. E-mail: mfonseca@fcsaude.ubi.pt

\section{Introduction}

Worldwide prevalence studies indicate that there are at least 347 million individuals with diabetes. Published data indicate that $20-50 \%$ of patients with type 2 diabetes develop diabetic nephropathy (DN) during their lives [1].

$\mathrm{DN}$ is characterized by kidney damage, which occurs as the result of both direct and indirect actions of glucose. These include oxidative stress, advanced glycation and activation of some cytokines [2, 3]. DN is thus a major cause of chronic kidney disease that progresses to end-stage renal disease (ESRD) [4].

One of the features of renal function loss is the elevated concentration of blood urea, which leads to the presence of hypercytokinemia, likely due to the accumulation of proinflammatory cytokines as a consequence of decreased renal elimination [5-7]. Th1, Th2 and Th17 cytokines also take part in the pathophysiology of DN [8].

Both innate and adaptative immunity are dysregulated in patients with ESRD [9, 10]. Regarding cellular adaptative immune response, it was shown that ESRD is characterized by anomalies in different features, such as in the $\mathrm{CD} 4 / \mathrm{CD} 8$ ratio, $\mathrm{CD} 4 \mathrm{~T}$ cell function, $\mathrm{T}$ cells response to stimuli, their activation profile and impaired signals from accessory molecules [11-13]. The pro-inflammatory cytokines IL-1, IL- 6 and TNF- $\alpha$ were studied in patients under haemodialysis [14, 15]. Moreover, it was demonstrated that among patients with ESRD, T effector memory CD4 and CD8 $\mathrm{T}$ cells, as well as total CD8 $\mathrm{T}$ cells, were higher in diabetic than in non-diabetic patients, strengthening the idea that different disease aetiologies can show different haemodialysis effects on T cells [16].

Although a number of studies were published on the role of $\mathrm{T}$ cell in type $2 \mathrm{DN}$ haemodialysis [17], publications reporting activation-related parameters on $\mathrm{T}$ cells and cytokine secretion using samples from patients with ESRD undergoing dialysis and healthy individuals generated different results. Moreover, very few studies have focused on the effect of a single HD treatment on T cell physiology and cytokine production [16, 18-20]. Therefore, the main 
objective of this study was to compare the following parameters in an homogeneous group of $\mathrm{DN}$ patients regarding aetiology and treatment before and after a dialysis session: (1) the proportions of $\mathrm{T}$ cells and their major subpopulations CD4 and CD8, (2) the expression of activation markers (CD25, CD69 and CD71) in total T cells and CD4 and CD8 $\mathrm{T}$ cell subpopulation and (3) the serum levels of the cytokines IL-8, IL- $1 \beta$, IL-6, IL-10, TNF- $\alpha$ and IL-12p 70 . To our knowledge, this study is the first to analyse these parameters in a homogeneous group of DN patients.

\section{Materials and methods}

Patients. The study group included 17 patients $(7 \mathrm{men} / 10$ women) with diabetic nephropathy (DN) undergoing haemodialysis at the Dialysis Center Fresenius Medical Care in Covilhã (a Portuguese inner city) for more than one year. All patients were non-smokers and had diabetes mellitus type 2 . All patients had the same vascular access (intravenous fistula), and none of them had had a transplant. Individuals who received immunosuppressive drugs were excluded. The mean age $( \pm \mathrm{SD})$ was $72.4 \pm 10.2$. All the patients were informed of the objectives of the study and signed an informed consent form. The project was submitted and approved by the Fresenius Medical Care ethics committee in accordance with both the Declaration of Helsinki and the Declaration of Istanbul 2008.

$T$ cell activation markers analysis by flow cytometry. Peripheral venous blood samples were collected before and after HD, into EDTA tubes. Analysis of activation markers analysis was carried out by four-colour flow cytometry using phycoerythrin (PE)-conjugated anti-CD25, antiCD69 and anti-CD71 (Becton-Dickinson Pharmingen, San Jose, CA, USA), peridinin chlorophyll protein (PerCP)-conjugated anti-CD8 (Miltenyi Biotec, Bergisch Gladbach, Germany), allophycocyanin (APC)-conjugated anti-CD3 (Becton-Dickinson Pharmingen) and fluorescein isothiocyanate (FITC)-conjugated anti-CD4 (Becton-Dickinson Pharmingen). The total blood was incubated with each of the above antibodies on ice for $15 \mathrm{~min}$ in the dark, following the manufacturer's instructions. The cells were then incubated in $1 \mathrm{ml}$ of BD FACS (BD Biosciences, San Jose, CA, USA) lysing solution for $15 \mathrm{~min}$ in the dark. After the lysis of the red blood cells, the cell suspension was washed twice with PBS to remove red blood cell remnants and the leucocytes were resuspended in $400 \mu \mathrm{L}$ of PBS and placed on ice in the dark until acquisition. Analysis of activation markers was carried out by fourcolour analysis using a FACSCalibur flow cytometer and CELLQUeST software (BD Biosciences). For each sample, data from 15000 cells were collected and analysed.

Cytokine analysis. The blood samples were collected before and after HD session into tubes without anticoagulant. Serum was separated after centrifugation at $20{ }^{\circ} \mathrm{C}$, $3000 \mathrm{~g}$ for $10 \mathrm{~min}$. These samples were frozen in cryopreservation tubes until assessed by flow cytometry. Serum IL-8, IL-1 $\beta$, IL-6, IL-10, TNF- $\alpha$ and IL-12p70 levels were determined using the Cytometric Bead Array Human Inflammatory Cytokines kit (Becton-Dickinson Pharmingen, 551811), following the manufacturer's instructions.

Statistical analysis. To compare the relative percentage of CD3, CD4 and CD8 cells; activation markers CD25, CD69 and CD71 in T subsets; and cytokines IL-8, IL-1 $\beta$, IL-6, IL-10, TNF- $\alpha$ and IL-12p70, before and after HD, we used the Wilcoxon signed-rank test. Pearson's and Spearman's rank correlation test was performed to determine the relationships between continuous variables. $P$ values $<0.05$ were considered statistically significant. sPss version 22 was used for data analysis.

\section{Results}

\section{Baseline laboratory characteristics of the study population}

Data regarding routine laboratory blood tests and dialysis efficacy performed at the time of the blood collection for the present work are presented in the Table 1. Specific haematological parameters are presented in Table 2.

\section{Analysis of activation markers on T cells}

We analysed the effect of HD on T cells and their major subpopulations, CD4 and CD8. There was an increase in the percentage of $\mathrm{CD} 3 \mathrm{CD} 4$ cells after the HD session, 62.3 (43.8-81.2) versus 68.1 (53-89) $P=0,042$. Inversely, the relative percentage of $\mathrm{CD} 3 \mathrm{CD} 8$ decreased (33.5 (15.549.7) versus 28.7 (9.2-40.8), $P=0,000056)$ after the HD session. As a consequence, there was a significant increase (26\%) in the CD4/CD8 ratio, after the HD session (1.9 (0.9-5.2) versus 2.4 (1.3-9.6), 0,042. The increase in the relative percentage of $\mathrm{CD} 3$-positive cells observed after the HD was not statistically significant (Fig. 1).

Regarding the expression of activation markers on $\mathrm{T}$ cells and their major subpopulations, we found statistically significant differences in the $T$ cell $\mathrm{CD} 25$ population $[33.7$ (4.3-58.2) versus 34.3 (11.5-64.1), $P=0,013]$, T CD8 CD25 cells [6.7 (1-15.4) versus 6.9 (1.1-25.4), $P=0,002]$ and T CD69 cells [9 (0.4-30.2) versus $6.4(1.1-14.7)$, $P=0,022]$, where there was a $29 \%$ decrease in the relative percentage after HD session (Fig. 2).

We also analysed the mean fluorescence intensity (MFI) of the expression of activation markers in total $\mathrm{T}$ cells, and CD 4 and CD8 subpopulations. We found that after the $\mathrm{HD}$ session, there was a significant decrease in CD4 T cells expressing CD25 [62.5 (23.8-88.1) versus 55.3 (23-71.6), $P<0,037]$. Moreover, CD71 MFI also decreased in total $\mathrm{T}$ cells [25.5 (10.9-84) versus 18.6 (6.6-49), 0,022], as well as in CD4 T cells [25.4 (10.9-59.3) versus 18.2 (6.5-54.9), $P=0,012]$ and in CD8 T cells [27.8 (0-120.8) 
Table 1 Laboratory characteristics and haemodialysis-related parameters of the population studied.

\begin{tabular}{|c|c|c|c|c|c|c|c|c|}
\hline Patient ID & $\begin{array}{l}\text { Creatinine } \\
(\mathrm{mg} / \mathrm{dl})\end{array}$ & $\begin{array}{l}C \text { reactive } \\
\text { protein } \\
(\mathrm{mg} / \mathrm{l})\end{array}$ & PTH (pg/ml) & $\begin{array}{l}\text { Transferrin } \\
(\mathrm{mg} / \mathrm{dl})\end{array}$ & $\begin{array}{l}\mathrm{HbA1c} \\
(\%)\end{array}$ & $\begin{array}{l}\text { Glycaemia } \\
(\mathrm{mg} / \mathrm{dl})\end{array}$ & $\begin{array}{l}\text { Erythropoietin } \\
\text { ( } \mu \mathrm{g} / \mathrm{month})\end{array}$ & $\mathrm{eKt} / \mathrm{V}$ \\
\hline 1 & 8.96 & 6 & 55.39 & 156 & 7.6 & 155.8 & 40 & 1.67 \\
\hline 2 & 8.45 & 4.2 & 133.3 & 216 & 7.4 & 95.8 & 80 & 1.79 \\
\hline 3 & 5.17 & 4.6 & 88.44 & 163 & 7.6 & 129.5 & 80 & 1.80 \\
\hline 4 & 7.41 & 3.8 & 175.9 & 167 & 9.1 & 164.4 & 40 & 1.84 \\
\hline 5 & 5.71 & 3.4 & 40.11 & 312 & 8.5 & 263.9 & No data & 2.14 \\
\hline 6 & 7.42 & 11.2 & 329 & 178 & 7 & 67.8 & 40 & 1.71 \\
\hline 7 & 7.52 & 1 & 176.9 & 136 & 5.8 & 47.9 & 80 & 1.68 \\
\hline 8 & 8.15 & 8.1 & 336.1 & 139 & 5.7 & 183.7 & 120 & 1.69 \\
\hline 9 & 7.34 & 5.5 & 224.6 & 154 & 8.9 & 109.1 & 80 & 1.75 \\
\hline 10 & 7.07 & 4.8 & 424.1 & 153 & 7.4 & 202.5 & 80 & 2.17 \\
\hline 11 & 8.03 & 17.3 & 414.5 & 182 & 9 & 220.6 & 40 & 2.46 \\
\hline 12 & 5.14 & 2.6 & 228 & 224 & 9 & 163.8 & 40 & 1.57 \\
\hline 13 & 4.14 & 6.4 & 220.6 & 118 & 7 & 265.2 & 160 & 1.10 \\
\hline 14 & 7.01 & 3.6 & 264.7 & 123 & 6.5 & 192.1 & 40 & 2.20 \\
\hline 15 & 5.55 & 2.9 & 42.29 & 180 & 6.5 & 171.9 & 80 & 1.94 \\
\hline 16 & 7.61 & 10.4 & 276 & 165 & 8 & 182.1 & No data & 1.33 \\
\hline 17 & 5.56 & 5.8 & 265.6 & 159 & 8.4 & 255.2 & 80 & 1.83 \\
\hline Med $[\min -\max ]$ & $7.3[4.1-9.0]$ & $\begin{array}{l}4.8 \\
\quad[1.0-17.3]\end{array}$ & $\begin{array}{l}224.6 \\
{[40.1-424.1]}\end{array}$ & $\begin{array}{l}163.0 \\
{[118.0-312.0]}\end{array}$ & $\begin{array}{l}7.6 \\
{[5.7-9.1]}\end{array}$ & $\begin{array}{l}171.9 \\
{[47.9-265.2]}\end{array}$ & $80[40-120]$ & $1.8[1.1-2.5]$ \\
\hline
\end{tabular}

PTH, parathyroid hormone; Med, median.

Table 2 Haematological parameters of the population studied.

\begin{tabular}{|c|c|c|c|c|c|c|c|c|}
\hline Patient ID & $\begin{array}{l}\text { Haemoglobin } \\
(\mathrm{g} / \mathrm{dl})\end{array}$ & WBC $(\mathrm{n} / \mu \mathrm{L})$ & $\begin{array}{l}\text { Neutrophils } \\
(\%)\end{array}$ & $\begin{array}{l}\text { Basophils } \\
(\%)\end{array}$ & $\begin{array}{l}\text { Monocytes } \\
(\%)\end{array}$ & $\begin{array}{l}\text { Lymphocytes } \\
(\%)\end{array}$ & $\begin{array}{l}\text { Eosinophils } \\
(\%)\end{array}$ & NLR \\
\hline 1 & 11.1 & 10000 & 71.1 & 0.1 & 4.1 & 21.4 & 3.3 & 3.3 \\
\hline 2 & 11.2 & 5300 & 45.1 & 0.3 & 7.7 & 44.2 & 2.7 & 1.0 \\
\hline 3 & 11.6 & 6700 & 66.5 & 0.4 & 6.1 & 19.8 & 7.2 & 3.4 \\
\hline 4 & 13.8 & 6700 & 67.2 & 0.2 & 9.1 & 20.0 & 3.5 & 3.4 \\
\hline 5 & 10.8 & 12000 & 61.3 & 0.2 & 5.8 & 30.0 & 2.7 & 2.0 \\
\hline 6 & 10.9 & 6500 & 62.6 & 0.2 & 6.1 & 27.7 & 3.4 & 2.3 \\
\hline 7 & 10.7 & 4900 & 63.4 & 0.1 & 5.4 & 26.1 & 5.0 & 2.4 \\
\hline 8 & 12.2 & 6700 & 73.6 & 0.2 & 7.6 & 15.1 & 3.5 & 4.9 \\
\hline 9 & 11.4 & 9900 & 59.8 & 0.1 & 7.5 & 30.4 & 2.2 & 2.0 \\
\hline 10 & 11.1 & 5400 & 65.3 & 0.0 & 7.0 & 25.1 & 2.6 & 2.6 \\
\hline 11 & 12.9 & 6000 & 63.5 & 0.2 & 6.9 & 26.0 & 3.4 & 2.4 \\
\hline 12 & 12.9 & 6200 & 59.0 & 0.3 & 5.1 & 24.8 & 10.8 & 2.4 \\
\hline 13 & 10.8 & 4900 & 61.3 & 0.0 & 2.9 & 34.2 & 1.6 & 1.8 \\
\hline 14 & 10.5 & 8200 & 67.7 & 0.2 & 5.8 & 23.6 & 2.7 & 2.9 \\
\hline 15 & 11.9 & 11400 & 82.7 & 0.1 & 5.8 & 8.9 & 2.5 & 9.3 \\
\hline 16 & 12.7 & 10600 & 67.2 & 0.2 & 5.2 & 25.3 & 2.1 & 2.7 \\
\hline 17 & 13.4 & 6500 & 71.5 & 0.1 & 9.7 & 16.8 & 1.9 & 4.3 \\
\hline $\operatorname{Med}[\min -\max ]$ & $\begin{array}{l}11.4 \\
{[10.5-13.8]}\end{array}$ & $\begin{array}{l}6700 \\
{[4900-12000]}\end{array}$ & $\begin{array}{l}65.3 \\
{[45.1-82.7]}\end{array}$ & $\begin{array}{l}0.2 \\
{[0-0.4]}\end{array}$ & $\begin{array}{l}6.1 \\
\quad[2.9-9.7]\end{array}$ & $\begin{array}{l}25.1 \\
{[8.9-44.2]}\end{array}$ & $\begin{array}{l}2.7 \\
{[1.6-10.8]}\end{array}$ & $2.6[1.0-9.3]$ \\
\hline
\end{tabular}

NLR, neutrophil to lymphocyte ratio; WBC, white blood cells.

versus $21.4(5.8-59.8), P=0.03]$. Concerning the other cell populations expressing CD25, CD69 and CD71, no significant differences were observed (Fig. 3).

\section{Cytokine analysis}

Figure 4 (A, B and C) represents serum levels of IL-10, IL- 6 and IL- 8 in samples taken before and after HD which were analysed by cytometric bead array. IL-10 (2.1 (1.4-
3.8) $\mathrm{pg} / \mathrm{ml}$ versus $2.4(1.6-4.2) \mathrm{pg} / \mathrm{ml}, P<0.05)$ and IL-6 $(6.7 \quad(2.4-24.9) \mathrm{pg} / \mathrm{ml}$ versus $7.9 \quad(3.3-31.4) \mathrm{pg} / \mathrm{ml}$, $P<0.05)$ concentrations increased after the HD session. Data on IL-8 concentration showed that after the HD session, the levels decreased significantly [18 (9.1-26.9) $\mathrm{pg} / \mathrm{ml}$ versus $10.3(5.8-20.2) \mathrm{pg} / \mathrm{ml}, P<0.05]$. Significant differences were not observed for IL-12p70, TNF- $\alpha$ and IL$1 \beta$ serum concentration between pre- and post-dialysis samples (data not shown). We analysed the possible 


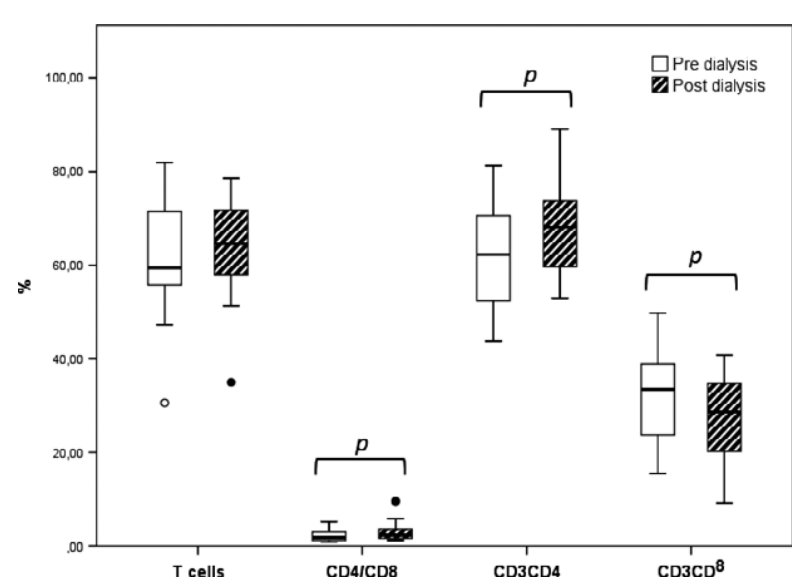

Figure 1 Analysis of the effect of haemodialysis on the percentage of peripheral blood CD4 and CD8 T cells by flow cytometry. Median values of the relative percentages of total T cells, CD4 and CD8 subpopulations and $\mathrm{CD} 4 / \mathrm{CD} 8$ ratio before and after HD are shown (the letter ' $p$ ' means that predialysis and post-dialysis data are statistically different $(P<0.05)$ $n=17)$.

correlation of cytokine levels with the haematological parameters, and no significant correlations were obtained.

\section{Discussion}

A significant proportion of patients with diabetes ultimately develop diabetic nephropathy [21]. Dialysis causes some relevant changes in the immune system, namely in the activation of complement [22], in the function of monocyte-derived dendritic cells [23] and in the release of various pro-inflammatory cytokines [24]. In this study, we set forth to further investigate some aspects associated with the activation of $\mathrm{T}$ lymphocytes, and with the levels of serum inflammatory cytokines. Many studies have focused on the comparison between healthy volunteers and HD patients on these parameters, but very few have focused on changes that occur after a single HD session in the same individual.

Regarding the relative percentage of CD8 T cells, we found a significant reduction after the HD session, consistent with the previous studies [16]. However, the results also revealed an increase in the T CD4 subset, probably caused by the duration of the HD procedure (about $4 \mathrm{~h}$ ), which promoted a continuous state of activation of $\mathrm{T}$ cells, affecting CD4 and CD8 subsets differently. Also, it must be considered the probable consequences of the blood contact with the membrane of the dialyser and whether this contact can lead to $\mathrm{T}$ cell apoptosis not equally affecting both compartments [20]. Overall, our results were consistent with other authors regarding the $\mathrm{CD} 4 / \mathrm{CD} 8$ ratio, showing an increase in this value after $\mathrm{HD}$ session.

Due to the crucial importance of $\mathrm{T}$ cells in the immune response, the study of the expression of their surface activation markers is very important to establish immunocompetence [25]; this was performed before and after the HD session. It is important to bear in mind that antigenand mitogen-driven $\mathrm{T}$ cell activation is known to result in the expression of activation markers in an orderly sequence: CD69, CD25, CD71 and HLA-DR [26]. Our results showed that HD caused an increase in the activation of total $\mathrm{T}$ cells, and particularly in CD8 compartment as measured by the CD25 expression. CD8 T cell subset could be more susceptible to the stimulus caused by the dialyser membrane when compared to CD4 T cells. As CD69 is the earliest activation marker to be expressed after $\mathrm{T}$ cells are stimulated and our samples were analysed at an interval of 2-6 h after blood collection, this may be a possible reason to justify the decrease in percentage when compared to the expression of CD25 on total $\mathrm{T}$ cells, which is expressed in minutes to hours after activation. Probably time between the collection of blood samples and flow cytometric analysis was a limitation of the study, and future

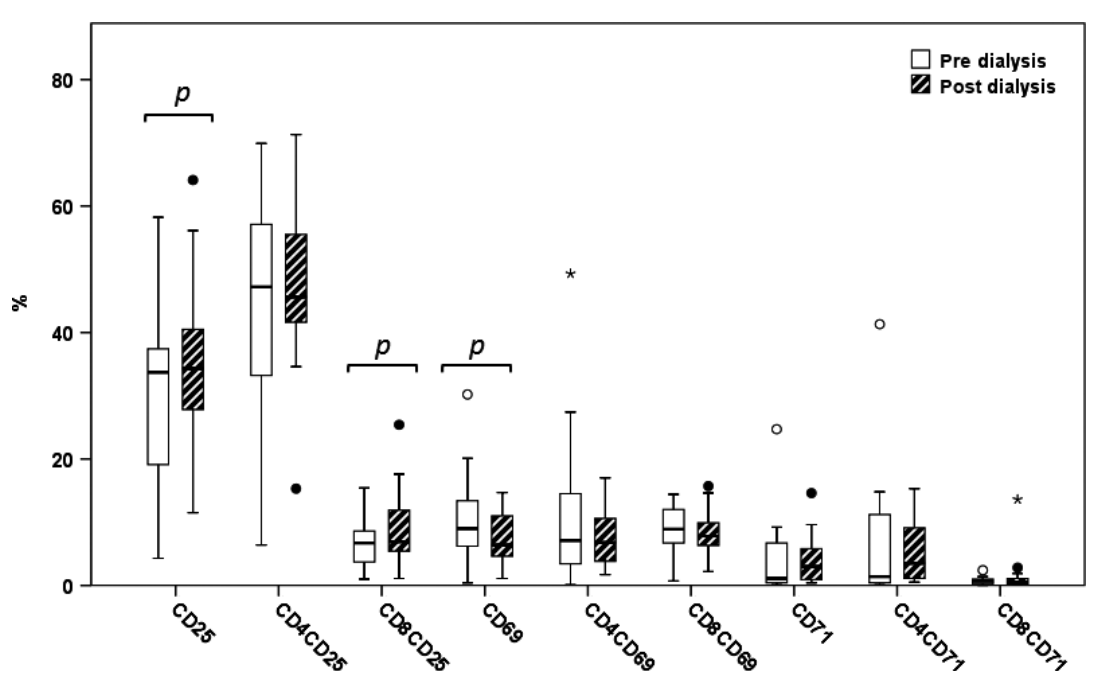

Figure 2 Analysis of the effect of haemodialysis on the percentage of activation markers on $\mathrm{T}$ cells and their major subpopulations by flow cytometry. Median values of the relative percentages of expression of $\mathrm{CD} 25, \mathrm{CD} 69$ and $\mathrm{CD} 71$ in total T cells and CD4 and CD8 subpopulations, before and after $\mathrm{HD}$, in 17 patients with diabetes are shown (the letter ' $p$ ' means that predialysis and postdialysis data are statistically different $(P<0.05) n=17)$ 
Figure 3 Analysis of the effect of haemodialysis on the level of expression of activation markers in total T cells, CD4 and CD8 subpopulations by flow cytometry. Values of the mean fluorescence intensity (MFI) of $\mathrm{T}$ cells and their subpopulations (CD4 and CD8) that express CD25, CD69 and $\mathrm{CD} 71$, before and after HD, in 17 patients with diabetes are shown (the letter ' $p$ ' means that pre- dialysis and post-dialysis data are statistically different $(P<0.05) n=17)$.

experiments have to be carried out in order to understand whether this constraint may or may not have an influence on the immunophenotyping results.

The values of mean fluorescence intensity (MFI) were also compared before and after HD for each activationrelated molecule. This parameter is proportional to the cell density of the molecules analysed per cell. We observed a reduction in the MFI of T CD4CD25 cells and a decrease in both $\mathrm{T}$ cell subsets regarding CD71 expression levels, after the HD session. CD71 binds the complex Fe (APO)transferrin by endocytosis, delivering iron, an important co-factor of enzymes necessary for cell growth and metabolism. Consistent with this analysis are the results of the last examinations performed before blood collection, where it was verified that approximately $82 \%$ of the patients had transferrin values below the reference values (200-360 mg/ml). Although the value of MFI after HD did not change significantly concerning the CD25 marker, a $P$ value was yielded near $0.05(P=0.054)$, which may be an indicator that there is a tendency for this value to decrease. To confirm this hypothesis, a higher number of volunteers would be required.

It is well known that inflammatory cytokines are involved in the development and progression of diabetic nephropathy $[8,27]$. We analysed the synthesis of IL-12p70, IL-8, IL-10, IL- $1 \beta$, TNF- $\alpha$ and IL-6 in serum samples taken before and after a single dialysis session for each volunteer. We found a significant increase in IL-10 and IL- 6 and a decrease in IL- 8 after the HD session. It was previously reported that serological concentration of IL-6 does not undergo significant alterations, but IL-8 concentration decreases following haemodialysis [18]. Regarding IL-6, our findings are not concordant with these; however, in this previous study, only 6 patients in a total of 29 had diabetes mellitus, and cytokine detection was determined by chemiluminescence enzyme immunometric assays, contrasting with flow cytometry used in the present report. Rysz's study with 15 patients observed an increase in the concentrations of IL- $1 \beta$, IL-6, IL- 8 and TNF- $\alpha$ after the 4h HD [19]. Adsorption evaluations of IL-1beta, IL-6 and TNF-alpha by different membrane dialysers showed that the HD effects are not the same [28]. Also, continuous haemofiltration increases IL-6 plasma clearance, but not TNF-alpha clearance [29]. These data were obtained with diverse experimental approaches, making it impossible to clearly understand what is really happening during HD.

An increase in IL-10 levels appears to function as a regulating mechanism to control uraemia and the activation induced by dialysis [30]. Through the inhibition of IL- $1 \beta$, TNF- $\alpha$ and IL- 8 , involved in the activation of granulocytes, monocytes-macrophages and NK, T and B cells, IL-10 regulates inflammatory process [31]. Our results are consistent with those findings, where no significant differences occurred in the concentration of IL- $1 \beta$ and TNF- $\alpha$ after HD, and there was a decrease in the concentration of IL-8. Probably the fact that IL-8 has a low molecular weight makes its diffusion through the dialysis membrane easy to occur.

Other than our study, we found no other study reporting IL-12p70 levels pre- and post-dialysis in the literature. We should also consider that the fact that dialysis did not significantly affect the concentrations of IL$1 \beta$, TNF- $\alpha$ and IL-12p70 differences in our study may be due to methodological limitations. However, the range of detectable values by the CBA is rather wide, 20-5000 pg/ $\mathrm{ml}$, making it important to determine whether values below $20 \mathrm{pg} / \mathrm{ml}$ may or may not be physiologically relevant. A limitation of this study is the sample size. Thus, to confirm the consistency of these results, it is necessary to include a larger number of patients. Nevertheless, it is worth mentioning that IL- $1 \beta$ and TNF- $\alpha$ also remained unchanged in the Tarakçioflu report [18].

Finally, we also studied the possible correlation of cytokine levels with haematological parameters presented in Table 2. Regarding the neutrophil to lymphocyte ratio (NLR) that has been gaining interest as a marker of 


\section{IL-10 concentration}

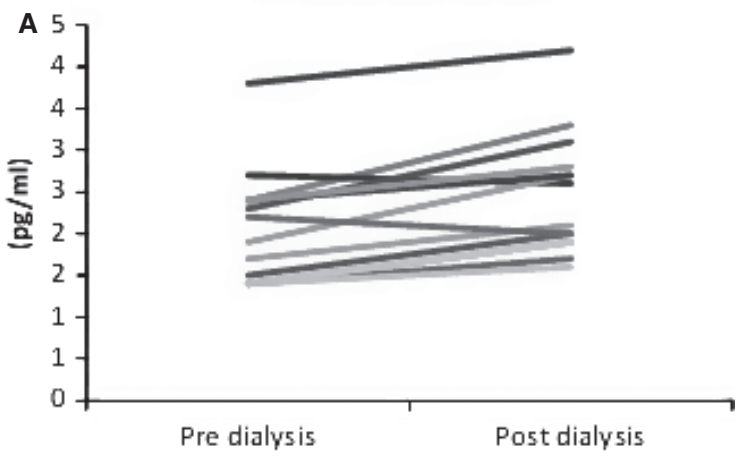

\section{IL-6 concentration}
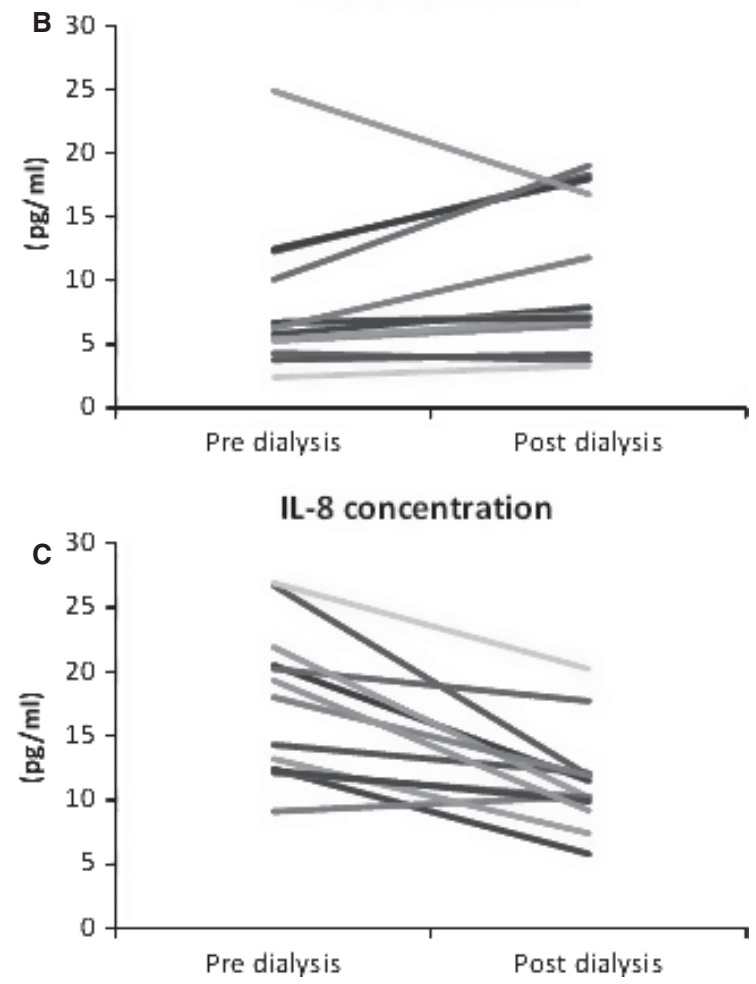

Figure 4 Quantifications of serum levels of IL-10, IL-6 and IL-8 from blood samples taken before and after the haemodialysis session analysed by cytometric bead array. Individual values of cytokines IL-10, IL-6 and IL-8 concentration, before and after $\mathrm{HD}$, expressed in $\mathrm{pg} / \mathrm{mL}$ are shown.

subclinical inflammation in chronic kidney disease such as dialysis patients [32], we did not find any correlation between NLR and inflammatory cytokines.

To our knowledge, our work is the first with a homogeneous group of DN patients to analyse the expression of activation markers on $\mathrm{T}$ cells and their major subpopulations, as well as the serum levels of inflammatory cytokines, in samples taken before and after dialysis in the same individuals. Through this study, it was found that HD does influence the expression of the marker CD25 in T cells and $\mathrm{CD} 8$ and CD69 expression on T cells. It was also found that after one HD session, density of CD71 molecules per cell decreased in $\mathrm{T}$ cells and $\mathrm{CD} 25$ molecules in CD4 T cells. Moreover, it was also verified that the HD session resulted in the increase in the concentration of IL-10 and IL6 and in a reduction in the concentration of IL- 8 after one $\mathrm{HD}$ session, possibly suggesting that these amendments are due to contact with the dialyser membrane. Nevertheless, the fact that there is an increase in the concentration of IL10 during the HD session implies that this treatment has immunomodulatory effect in the patients.

\section{Author statement}

All authors have contributed significantly for the paper. Fonseca A.M. and Lourenço O. gave substantial contributions to conception and design, and all three authors contributed to the acquisition, analysis and interpretation of data, drafting the article and revising it critically for important intellectual content.

\section{Conflict of interest statement}

All authors have declared no competing interest.

\section{Funding}

This work was supported by the Project CENTRO-07ST24-FEDER-002015 and PEst-OE/SAU/UI0709/2014 (UI 709 - 2014).

\section{References}

1 Adler AI, Stevens RJ, Manley SE et al. Development and progression of nephropathy in type 2 diabetes: the United Kingdom Prospective Diabetes Study (UKPDS 64). Kidney Int 2003;63:225-32.

2 Elmarakby AA, Sullivan JC. Relationship between oxidative stress and inflammatory cytokines in diabetic nephropathy. Cardiovasc Ther 2012;30:49-59.

3 Mima A. Inflammation and oxidative stress in diabetic nephropathy: new insights on its inhibition as new therapeutic targets. J Diabetes Res 2013;2013:248563.

4 Vallon V, Komers R. Pathophysiology of the diabetic kidney. Compr Physiol 2011;1:1175-232.

5 Kimmel P, Phillips T, Simmens $\mathrm{S}$ et al. Immunologic function and survival in hemodialysis patients. Kidney Int 1998;54:236-44.

6 Stenvinkel P, Ketteler M, Johnson R et al. IL-10, IL-6, and TNFalpha: central factors in the altered cytokine network of uremia-the good, the bad, and the ugly. Kidney Int 2005;67:1216-33.

7 Lim AK, Tesch GH. Inflammation in diabetic nephropathy. Mediators Inflamm 2012;2012:146154.

8 Wu CC, Sytwu HK, Lin YF. Cytokines in diabetic nephropathy. Adv Clin Chem 2012;56:55-74.

9 Eleftheriadis T, Antoniadi G, Liakopoulos V, Kartsios C, Stefanidis I. Disturbances of acquired immunity in hemodialysis patients. Semin Dial 2007;20:440-51.

10 Kato S, Chmielewski M, Honda $\mathrm{H}$ et al. Aspects of immune dysfunction in end-stage renal disease. Clin $J$ Am Soc Nephrol 2008;5:1526-33.

11 Meier P, Golshayan D, Blanc E, Pascual M, Burnier M. Oxidized LDL modulates apoptosis of regulatory $\mathrm{T}$ cells in patients with ESRD. J Am Soc Nephrol 2009;20:1368-84. 
12 Dietzmann J, Thiel U, Ansorge S, Neumann K, Tager M. Thiolinducing and immunoregulatory effects of flavonoids in peripheral blood mononuclear cells from patients with end-stage diabetic nephropathy. Free Radic Biol Med 2002;33:1347-54.

13 Girndt M, Sester U, Sester M, Kaul H, Kohler H. Defective expression of B7-2 (CD86) on monocytes of dialysis patients correlates to the uremia-associated immune defect. Kidney Int 2001;59:1382-9.

14 Girndt M, Sester U, Kaul H, Köhler H. Production of proinflammatory and regulatory monokines in hemodialysis patients shown at a single-cell level. J Am Soc Nephrol 1998;9:1689-96.

15 Herbelin A, Nguyen A, Zingraff J, Ureña P, Descamps-Latscha B. Influence of uremia and hemodialysis on circulating interleukin-1 and tumor necrosis factor $\alpha$. Kidney Int 1990;37:116-25.

16 Yoon J-W, Gollapudi S, Pahl MV, Vaziri ND. Naive and central memory T-cell lymphopenia in end-stage renal disease. Kidney Int 2006;70:371-6.

17 Wu CC, Sytwu HK, Lu KC, Lin YF. Role of T cells in type 2 diabetic nephropathy. Exp Diabetes Res 2011;2011:514738.

18 Tarakçioglu M, Erbagci A, Usalan C, Deveci R, Kocabas R. Acute effect of hemodialysis on serum levels of the proinflammatory cytokines. Mediators Inflamm 2003;12:15-9.

19 Rysz J, Banach M, Cialkowska-Rysz A et al. Blood serum levels of IL2, IL-6, IL-8, TNF-alpha and IL-1beta in patients on maintenance hemodialysis. Cell Mol Immunol 2006;2:151-4.

20 Borges A, Borges M, Fernandes J et al. Apoptosis of peripheral CD4+ -lymphocytes in end-stage renal disease patients under hemodialysis and rhEPO therapies. Ren Fail 2011;33:138-43.

21 Dronavalli S, Duka I, Bakris GL. The pathogenesis of diabetic nephropathy. Nat Clin Pract Endocrinol Metab 2008;8:444-52.

22 DeAngelis RA, Reis ES, Ricklin D, Lambris JD. Targeted complement inhibition as a promising strategy for preventing inflammatory complications in hemodialysis. Immunobiology 2012;217:1097-105.
23 Choi HM, Woo YS, Kim MG, Jo SK, Cho WY, Kim HK. Altered monocyte-derived dendritic cell function in patients on hemodialysis: a culprit for underlying impaired immune responses. Clin Exp Nephrol 2011;4:546-53.

24 Zamauskaite A, Perez-Cruz I, Yaqoob M, Madrigal J, Cohen S. Effect of renal dialysis therapy modality on $\mathrm{T}$ cell cytokine production. Nephrol Dial Transplant 1999;14:49-55.

25 Shipkova M, Wieland E. Surface markers of lymphocyte activation and markers of cell proliferation. Clin Chim Acta 2012;413:133849.

26 Caruso A, Licenziati S, Corulli M et al. Flow cytometric analysis of activation markers on stimulated $\mathrm{T}$ cells and their correlation with cell proliferation. Cytometry 1997;27:71-6.

27 Navarro-González JF, Mora-Fernández C. The role of inflammatory cytokines in diabetic nephropathy. $J$ Am Soc Nephrol 2008;3: 433-42.

28 Fujimori A, Naito H, Miyazaki T. Adsorption of complement, cytokines, and proteins by different dialysis membrane materials: evaluation by confocal laser scanning fluorescence microscopy. Artif Organs 1998;12:1014-7.

29 Sander A, Armbruster W, Sander B, Daul AE, Lange R, Peters J. Hemofiltration increases IL-6 clearance in early systemic inflammatory response syndrome but does not alter IL- 6 and TNF alpha plasma concentrations. Intensive Care Med 1997;8:878-84.

30 Girndt M, Ulrich C, Kaul H, Sester U, Sester M, Hohler H. Uremiaassociated immune defect: the IL-10 - CRP axis. Kidney Int 2003;63: S76-9.

31 Steensberg A, Fisher C, Keller C, Moller K, Pedersen K. IL-6 enhances plasma IL-1 ra, IL-10, and cortisol in humans. Am J Physiol Endocrinol Metab 2003;285:E433-7.

32 Okyay GU, Inal S, Oneç K et al. Neutrophil to lymphocyte ratio in evaluation of inflammation in patients with chronic kidney disease. Ren Fail 2013;35:29-36. 